\title{
Simple models and concepts as tools for the study of sustained soil productivity in long-term experiments. II. Crop nutrient equivalents, balanced supplies of available nutrients, and NPK triangles
}

\author{
Bert H. Janssen
}

Received: 23 November 2009/Accepted: 9 September 2010 /Published online: 12 October 2010

(C) The Author(s) 2010. This article is published with open access at Springerlink.com

available $\mathrm{N}: \mathrm{P}: \mathrm{K}$ revealed low $\mathrm{N}$, very high $\mathrm{K}$ and medium P. Recovery of fertilizer $\mathrm{N}$ was high because of capillary rise of groundwater and absence of leaching. In both trials, first-season chemical crop analysis would directly have detected disproportions of soil available N, P and K. This knowledge could have improved the experimental designs, optimized nutrient use efficiency and minimized losses of $\mathrm{N}$ and $\mathrm{K}$ to the environment.

Keywords Agronomic nutrient use efficiency . Factorial experiments · Flevopolder · Mekong delta . Physiological nutrient use efficiency $\cdot$ Residual P recovery
Abbreviations
A
Amount of a nutrient in available form
$\mathrm{CF}$
Conversion factor for the translation of $\mathrm{kCNE}$ into $\mathrm{kg}$
CNE Crop nutrient equivalent
F Flevoland (stands at the front of an acronym)
ISF Ideal soil fertility
IA Input of available nutrients
IU Nutrient uptake from input
M Mekong (stands at the front of an acronym)
PhE Physiological nutrient use efficiency
PhEmax Maximum physiological nutrient use efficiency
PhEmed Medium physiological nutrient use efficiency 


\begin{tabular}{|c|c|}
\hline hEmin & $\begin{array}{l}\text { Minimum physiological nutrient use } \\
\text { efficiency }\end{array}$ \\
\hline QUEFTS & $\begin{array}{l}\text { Quantitative Evaluation of the Fertility of } \\
\text { Tropical Soils }\end{array}$ \\
\hline REC & Recovery fraction of input nutrients \\
\hline $\mathrm{REC}_{\mathrm{t}}$ & Residual recovery fraction in year (season) $t$ \\
\hline $\mathrm{REC}_{\mathrm{nt}}$ & $\begin{array}{l}\text { Total recovery in year (season) } t \text { after } n \\
\text { equally large applications }\end{array}$ \\
\hline SA & Soil available nutrients \\
\hline SOC & Soil organic carbon \\
\hline SON & Soil organic nitrogen \\
\hline SU & Nutrient uptake from soil \\
\hline TA & $\begin{array}{l}\text { Amount of available nutrients from soil } \\
\text { and input required for target yield }\end{array}$ \\
\hline TIA & $\begin{array}{l}\text { Amount of available nutrients from input } \\
\text { required for target yield }\end{array}$ \\
\hline TU & $\begin{array}{l}\text { Uptake of a nutrient required for target } \\
\text { yield }\end{array}$ \\
\hline TY & Target yield \\
\hline 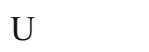 & Uptake of a nutrient \\
\hline 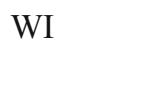 & $\begin{array}{l}\text { Whole input of a nutrient in available an } \\
\text { non-available form }\end{array}$ \\
\hline
\end{tabular}

\section{Introduction}

It was explained in the accompanying paper that the topic of sustainability is restricted to sustained soil productivity, so to the function of soil to promote plant growth and specifically to the provision of plant available mineral nutrients. Soil productivity is considered a basic necessity, but environmental, economic and social conditions finally determine whether agricultural practices will be sustainable.

Numerous studies deal with the role of soil organic matter in sustaining soil productivity (Weil and Magdoff 2004). As long as soil organic matter remains above a certain critical level to guarantee soil structural stability, a decline of SOM does not mean that sustainability is at risk (Feller and Beare 1997; Loveland and Webb 2003). The emphasis on organic matter and $\mathrm{N}$, however, bears the risk that the role of nutrients other than $\mathrm{N}$ is overlooked. For a good understanding of the results of long-term (fertilizer) trials, data on the uptake by the crop of the nutrients is indispensable. As appeared in the accompanying paper such information often is not available, likely because the costs involved in chemical analysis of crops have been prohibitive. Another reason why other nutrients than $\mathrm{N}$ frequently are not considered probably is the difficulty of handling all nutrients, or at least the three macro-nutrients $\mathrm{N}, \mathrm{P}$ and $\mathrm{K}$, at the same time. In this paper, the proportions of $\mathrm{N}, \mathrm{P}$ and $\mathrm{K}$ in nutrient supply and uptake will receive special attention. For that purpose some concepts are applied that were developed to deal with balanced $\mathrm{N}: \mathrm{P}: \mathrm{K}$ proportions and optimum nutrient management.

The outcomes of two long-term factorial NPK trials, carried out in different ecological settings were (re-) analyzed. The chosen trials contained treatments that did or did not lead to sustained soil productivity. The trials had been carried out in situtions where erosion, saltingup, acidification and the like did not occur.

The objective of the present study was to find and understand with the help of the introduced tools of crop nutrient equivalents and NPK triangles the causes of success of some and of failure of other NPK combinations, The discussion is narrowed down to the following questions:

- Why did some NPK combinations not result in increasing yields?

- Would it have been possible to foresee from the beginning which of the experimental treatments were to end up in unsustained soil productivity?

- How could balanced N:P:K availability have been achieved?

- What were major differences with regard to likelihood of sustained soil productivity between the two agroecosystems?

\section{Materials and methods}

Summary description of the long-term experiments

NPK factorial trial for rice monoculture in the Mekong River Delta of Viet Nam

A $2^{3}$ NPK experiment in the Mekong delta in Vietnam (Tan et al. 1995) was reanalyzed. Before 1975 the site was uncultivated natural wetland. Dry season is from December to March, wet season from April to August. From September to November the area is naturally flooded with deposition of fresh sediments. The soil is a heavy clay soil ( $57 \%$ clay). At the start, $\mathrm{pH}$ (1:1 water) was 5.7, P-Bray-2 and POlsen were 4 and $2.2 \mathrm{mg} / \mathrm{kg}$, respectively, SOC was 
$26 \mathrm{~g} \mathrm{~kg}^{-1}$, SON $2.8 \mathrm{~g} \mathrm{~kg}^{-1}$, and exchangeable $\mathrm{K}$ $2.3 \mathrm{mmolkg}^{-1}$. The trial started in the wet season of 1986, and ended with the dry season of 1993-1994. Application levels were 0 or 1 , where 1 was $80 \mathrm{~kg}$ of $\mathrm{N}, 17.5 \mathrm{~kg}$ of $\mathrm{P}$ and $25 \mathrm{~kg}$ of $\mathrm{K}$. Two crops of rice (dry and wet season) were grown. Irrigation water levels were maintained at around $10 \mathrm{~cm}$ for most of the growth period.

\section{NPK factorial trial on a former sea bottom in the Netherlands}

Between 1975 and 2002, an NPK factorial trial was carried out on soils in the former sea bottom in the Eastern Flevopolder, the Netherlands. The polder was reclaimed in 1957, and drainage on this site started in 1960. Between 1960 and 1974, 15 crops were grown, which together received $550 \mathrm{kgN}$ and $180 \mathrm{~kg}$ P. The soil was a loam to clay loam, containing $16 \mathrm{~g} \mathrm{~kg}^{-1}$ SOC, $106 \mathrm{gkg}^{-1} \mathrm{CaCO}_{3}$, and $\mathrm{pH}(\mathrm{KCl})$ was 7.3. In 1975, exchangeable $\mathrm{K}$ was $3.6 \mathrm{mmolkg}^{-1}$ and P-water $10 \mathrm{mgkg}^{-1}$. The long-term NPK trial started in 1975 with the aim to examine how long it would take to deplete these fertile soils. Sugar-beet, spring barley, potatoes, and winter wheat were grown in a 4-year rotation. Sometimes weather conditions forced to deviate from this scheme, and to grow maize or spring wheat. The experimental design was $2^{3}$ NPK in 3 replicates from 1975 to 1993 , and a $3 \mathrm{~N} \cdot 2^{2} \mathrm{PK}$ factorial in 2 replicates between 1994 and 2002. Application levels were 0 or 1 , where NPK at 1 was 150-65-41(62) $\mathrm{kgha}^{-1}$ for sugar-beet, 57.5-25-41 for cereal crops, and 200-87-41 for potatoes. The $\mathrm{N}$ applications at N1 and N2 since 1995 were two and four thirds, respectively, of the N1 levels before 1994. The crops grown in the period 1994-1999 were chemically analyzed.

So far the results have been presented in internal reports only, apart from a poster at the 16th Conference of the International Soil Science Society (Janssen and Menkveld 1998).

Time trends of yields and crop responses to applied NPK

Cumulative yields instead of seasonal yields were plotted versus time. They were described by 2 nd order polynomials forcing the regressions lines through the origin.
The response to applied $\mathrm{P}$ was analyzed using Eq. 1:

$$
\begin{aligned}
\mathrm{REC}_{\mathrm{nt}} & =\mathrm{REC}_{1}+\mathrm{REC}_{2}+\mathrm{REC}_{3}+\ldots . \mathrm{REC}_{\mathrm{n}} \\
& =\mathrm{REC}_{1} \cdot\left(1-\mathrm{q}^{\mathrm{n}}\right) /(1-\mathrm{q})
\end{aligned}
$$

where $\mathrm{REC}_{1}$ stands for the recovery fraction of fertilizer $\mathrm{P}$ in Year 1, $\mathrm{REC}_{\mathrm{t}}$ for the residual recovery fraction in Year $t$ of an application in Year 1, $\mathrm{REC}_{\mathrm{nt}}$ for the total recovery at time $t$ of $n$ successive equally large quantities of $\mathrm{P}$, and $\mathrm{q}$ is the ratio $\mathrm{RECt} / \mathrm{REC}_{(\mathrm{t}-1)}$ (Janssen and Wolf 1988). Details are explained in the accompanying paper.

Crop nutrient equivalents (CNE) and NPK triangles

It is inconvenient to judge whether $\mathrm{N}, \mathrm{P}$ and $\mathrm{K}$ are supplied and taken up in balanced proportions or not, when the amounts are given in $\mathrm{kg}$ per ha. That problem is avoided when the quantities of nutrients are expressed in crop nutrient equivalents (CNE). A (k)CNE of a nutrient is defined as the quantity of that nutrient that, under conditions of balanced nutrition, has the same effect on yield as $1(\mathrm{k}) \mathrm{g}$ of nitrogen (Janssen 1998). For maize, $1 \mathrm{kCNE}$ of $\mathrm{P}$ is $0.145 \mathrm{~kg}$ $\mathrm{P}$, and $1 \mathrm{kCNE}$ of $\mathrm{K}$ is $0.8 \mathrm{kgK}$ (see below for the calculation of the conversion factors).

The idea of crop nutrient equivalents (CNE) was derived from the model QUEFTS and the use of socalled NPK triangles is a further extension of it (Janssen et al. 1990; Janssen 1998). When the three nutrients, N, $\mathrm{P}$ and $\mathrm{K}$, are expressed in $(\mathrm{k}) \mathrm{CNE}$, it is possible and it makes sense to calculate what percentage each nutrient takes in the sum of the three. These percentages are plotted along the sides of a triangular diagram (Fig. 1). At any point in the triangle $\mathrm{FN}+\mathrm{FP}+\mathrm{FK}=100 \%$, where $\mathrm{F}$ stands for the fraction, expressed in $\%$, that the nutrient takes in the sum of FN, FP and FK. In the centre of the triangle, FN, FP and FK are each 33.3\%. The triangle can be used to depict the NPK composition of soil available supply (SA), input of available nutrients (IA), whole input (WI) being the sum of avaible and not available input nutrients, uptake from input (IU), uptake from soil (SU), and uptake from both $(\mathrm{U}=\mathrm{SU}+\mathrm{IU})$. The centre represents optimum nutrient uptake, in the case the triangle is used to show $\mathrm{U}$.

Calculations with the QUEFTS model (Janssen et al. 1990) show that approximately $95.5 \%$ of the 
available quantity of each nutrient (A) is taken up, so $\mathrm{U} / \mathrm{A}=0.955$ or $\mathrm{A} / \mathrm{U}=1.047$, when equal quantities of $\mathrm{N}, \mathrm{P}$ and $\mathrm{K}$ (expressed in $\mathrm{kCNE}$ ) are available. This implies that then the proportions of UN:UP:UK as well as the proportions of AN:AP:AK are 1:1:1. When the available quantities (from soil and input) are not balanced, the proportions of UN:UP:UK are closer to 1:1:1 than the proportions of AN:AP:AK. This is a consequence of the relatively more efficient uptake of the nutrient with limited availability than of nutrients that are abundantly available. (Janssen et al. 1990; Smaling and Janssen 1993). U/A of the nutrient in shortest supply may be 1 , while U/A of the other nutrients is $<0.955$, and may even be as small as 0.25 .

Assessment of nutrient use efficiency, crop nutrient equivalents, and crop available nutrients in soil and input by means of factorial experiments

Nutrient use efficiency is split into uptake efficiency and physiological efficiency. Uptake efficiency of

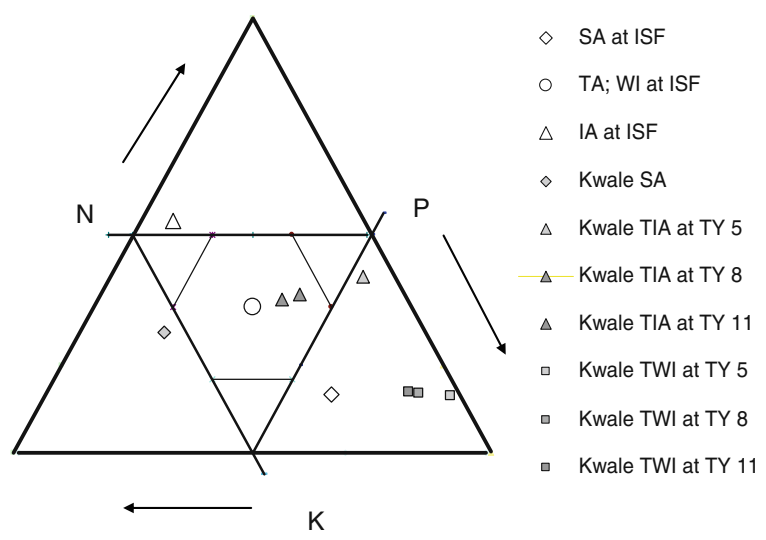

Fig. 1 NPK triangle. Along the sides, N, P and $\mathrm{K}$ run in the indicated direction from 0 to $100 \%$ of the sum of N, P and $\mathrm{K}$ (expressed in crop nutrient equivalents). At each point of the triangle, the sum of N, P and $\mathrm{K}$ is $100 \%$. The thick lines within the triangle indicate a fraction of $50 \%$ of the sum of $\mathrm{N}, \mathrm{P}$ and $\mathrm{K}$, and the thin lines indicate a fraction of $17 \%$. ISF stands for Ideal Soil Fertility. SA, IA and TA represent the NPK composition of the available nutrients from soil, from input and the target quantity of available nutrients (TA = SA + IA), respectively. Target inputs of available nutrients (TIA) and target whole input (TWI) for target maize yields (TY) of 5, 8 and $11 \mathrm{t} \mathrm{ha}^{-1}$ were calculated given the observed SA in Kwale (Smaling and Janssen 1993). Recovery fractions of input $\mathrm{N}, \mathrm{P}$ and $\mathrm{K}$ were set at $0.8,0.1$ and 0.6 at ISF, and at $0.5,0.1$ and 0.5 in Kwale, respectively. WI stands for whole input. For explanation see text and appendix input nutrients is synonymous to recovery fraction (REC), which is the ratio of IU/I, where I stands for input, and IU for nutrients taken up from input. Physiological efficiency (PhE) relates the yield (Y) of the economic plant components (e.g. grains, tubers) to uptake by the whole crop. Uptake efficiency is also called capture efficiency, and physiological efficiency sometimes is named conversion efficiency (Chikowo et al. 2010), but more often internal utilization efficiency (Witt et al. 1999). Because the acronyms IE and CE may lead to confusion as the letters 'I' and ' $\mathrm{C}$ ' have other meanings too in this article, the use of IE or CE is avoided.

$\mathrm{PhE}$ is highest when the nutrient is diluted in the crop, and lowest when the nutrient is accumulated. Both situations, maximum and minimum $\mathrm{PhE}$, represent unbalanced plant nutrition, where one nutrient (e.g. N) is strongly growth limiting and one or both other nutrients ( $\mathrm{P}$ and $\mathrm{K}$ ) are at unnecessarily high levels, or vice versa. The average $\mathrm{PhE}$ of all three nutrients is then less than maximum possible. The medium (PhEmed) position between dilution (PhEmax) and accumulation (PhEmin) represents the balanced situation, in which the average value of PhEN, PhEP and PhEK is maximum (Janssen 1998). The ratios PhENmed: PhEPmed, and PhENmed:PhEKmed are used as multiplication factors for the conversion of $\mathrm{kCNE}$ (crop nutrient equivalent) of $\mathrm{P}$ and $\mathrm{K}$ into $\mathrm{kg}$ of $\mathrm{P}$ and $\mathrm{K}$, respectively. For instance the conversion factor (CF) of $\mathrm{P}$ for spring barley is 60/200 (Table 1).

Factorial experiments offer good opportunities for the assessment of minimum and maximum $\mathrm{PhE}$, maximum uptake from soil, and maximum uptake from input. The maximum uptake from the soil (SUmax) is considered to represent the available supply by the soil (SA). In the case of N, P and K, the smallest suitable design is a $2^{3}$ factorial, in which each nutrient is found at two levels, presence or absence. Designs with more than two levels, e.g., $3^{3}$ would even be better, but require far more extensive trials. Table 2 shows which treatments were used in the present study, unless stated differently, for the estimation of PhEmax and PhEmin, SA and RECmax. The control (N0 P0 K0) cannot be used to estimate SA because the uptake of one nutrient from an unfertilized soil may be limited by retarded growth caused by deficiency of another nutrient. In principle, the recovery of input nutrients is calculated as the 
Table 1 Values of maximum, minimum and medium physiological nutrient use efficiency (PhE), and corresponding factors for the conversion of $\mathrm{kCNE}$ (crop nutrient equivalents) into $\mathrm{kg}$, as used in this paper

\begin{tabular}{|c|c|c|c|c|c|c|c|c|c|}
\hline \multirow[t]{2}{*}{$\mathrm{PhE}$} & \multicolumn{3}{|c|}{ Rice $^{a}$} & \multicolumn{3}{|c|}{ Spring barley ${ }^{\mathrm{b}}$} & \multicolumn{3}{|c|}{ Sugar-beet $^{\mathrm{b}}$} \\
\hline & $\mathrm{N}$ & $\mathrm{P}$ & $\mathrm{K}$ & $\mathrm{N}$ & $\mathrm{P}$ & $\mathrm{K}$ & $\mathrm{N}$ & $\mathrm{P}$ & $\mathrm{K}$ \\
\hline Maximum & 96 & 622 & 115 & 90 & 300 & 90 & 135 & 900 & 90 \\
\hline Minimum & 42 & 206 & 36 & 30 & 100 & 30 & 45 & 300 & 30 \\
\hline Medium & 69 & 414 & 76 & 60 & 200 & 60 & 90 & 600 & 60 \\
\hline Conversion factor (CF) & 1 & 0.167 & 0.91 & 1 & 0.3 & 1 & 1 & 0.15 & 1.5 \\
\hline
\end{tabular}

a From Witt et al. 1999

b From not-published reports on the Flevoland trial

difference between the treatments with and without that nutrient. The difference likely is the greatest (RECmax) for the treatments at the higher level of the other nutrients, e.g., N1P1K1- N0P1K1 for RECmax of fertilizer $\mathrm{N}$, as indicated in Table 2.

Nutrient inputs required for target yields

Yields estimated (YE) with the QUEFTS model are, in case of balanced nutrient uptake, approximately equal to $95.5 \%$ of the product of uptake times PhEmed. As U/A is then 0.955 (see above), YE is related to A by:

$$
\begin{aligned}
\mathrm{YE} & =0.955 \cdot \mathrm{U} \cdot \text { PhEmed } \\
& =0.91 \cdot \mathrm{A} \cdot \text { PhEmed }
\end{aligned}
$$

Equation 2 can also be used in a reverse way to calculate the amount of available nutrients (TA) required for a certain target yield (TY). In case the available soil supply (SA) is known, the target input of available nutrients (TIA) can be calculated as the difference between TA and SA. The input of available nutrients (IA) is part of the whole input (WI) of available and non-available nutrients: IA $=\mathrm{WI} \cdot \mathrm{RECmax}$. So, the target whole input (TWI) can be calculated if the maximum fertilizer recovery fraction (RECmax) is known:

$\mathrm{TA}=\mathrm{TY} /(0.91 \cdot \mathrm{PhEmed})$

$\mathrm{TIA}=\mathrm{TA}-\mathrm{SA}$

$\mathrm{TWI}=\mathrm{TIA} / \mathrm{RECmax}$

The soil supplies of available nutrients, SAN, SAP and SAK, seldom are equal. To arrive at balanced nutrient supplies by soil and input, TIAN, TIAP and TIAK must be adjusted to the NPK composition of SA, as well to the level of the target yield (TY). In the NPK triangle, the optimum compositions of TIA are found on the extension of the straight line through the points of SA and the centre of the triangle (Fig. 1).
Table 2 Treatments of a $2^{3}$ factorial preferably used for the assessment of minimum and maximum $\mathrm{PhE}$, supplies of soil available nutrients (SA), and maximum recovery fractions (RECmax). For RECmax two treatments are needed, e.g., N1P1K1-N1P1K0 for the estimation of

\begin{tabular}{|c|c|c|c|c|c|c|}
\hline \multicolumn{2}{|c|}{ Treatment code } & \multicolumn{3}{|l|}{$\mathrm{PhE}$} & \multirow[t]{2}{*}{ SA } & \multirow[t]{2}{*}{ RECmax } \\
\hline Full & Short & $\mathrm{N}$ & $\mathrm{P}$ & $\mathrm{K}$ & & \\
\hline N0 P0 K0 & Control & & & & & \\
\hline N0 P0 K1 & $\mathrm{K}$ & & & Min & & \\
\hline N0 P1 K0 & $\mathrm{P}$ & & Min & & & \\
\hline N0 P1 K1 & PK & Max & & & $\mathrm{N}$ & $\mathrm{N}$ \\
\hline N1 P0 K0 & $\mathrm{N}$ & Min & & & & \\
\hline N1 P0 K1 & NK & & Max & & $\mathrm{P}$ & $\mathrm{P}$ \\
\hline N1 P1 K0 & $\mathrm{NP}$ & & & $\operatorname{Max}$ & $\mathrm{K}$ & K \\
\hline N1 P1 K1 & NPK & & & & & $\mathrm{N}, \mathrm{P}, \mathrm{K}$ \\
\hline
\end{tabular}
RECmaxK 
The mathematical prove for this is given in the appendix. In Fig. 1, TIA and TWI are shown for maize TY's of 5, 8 and $11 \mathrm{t} \mathrm{ha}^{-1}$. The NPK composition of SA in Kwale, which is used as an example in Fig. 1, was (in $\mathrm{kgha}^{-1}$ ) $50.9: 4.7: 80.4$, as assessed in a field trial in Kenya (Smaling and Janssen 1993).

If a soil receives year after year nutrient inputs directed towards balanced amounts of available N, P and $\mathrm{K}$, the NPK composition of SA will change and finally the soil becomes low in $\mathrm{N}$, high in $\mathrm{P}$ and medium in $\mathrm{K}$. This is the composition at 'ideal soil fertility' (ISF), as explained in the appendix. The points of SA at ISF and the corresponding IA (high in $\mathrm{N}$, low in $\mathrm{P}$ and medium in $\mathrm{K}$ ) are also shown in Fig. 1.

\section{Results}

NPK factorial trial for rice monoculture in the Mekong River Delta of Viet Nam

\section{Yields, and responses to $N, P$ and $K$}

Rice yields and nutrient uptake (Tan et al. 1995) are shown in Table 3. Yields were lower in the wet than in the dry season, especially when no P was applied. In Fig. 2 cumulative yields are described by parabolic equations; the sign of the quadratic term indicates whether the yield trend was positive or negative during the experimental period. In the dry seasons (top graph), yields of all fertilizer treatments increased, but in the wet seasons (middle graph), yields decreased over time for treatments without $\mathrm{P}$, and hardly changed for treatments with P. A striking difference between the dry and wet season is that in the dry season Treatment $\mathrm{N}$ produced somewhat higher yields than Treatment $\mathrm{P}$, while in the wet seasons Treatment $\mathrm{P}$ gave considerably higher yields than Treatment N. Also shown in Fig. 2 (bottom) are the sums of the yields in the dry and wet seasons, i.e. the yields between two periods of natural flooding. The trial started with a wet season before the flood. Therefore the yields of the first dry and the second wet season, etc. had to be combined, resulting in seven periods. Treatments with $\mathrm{P}$ showed a slightly positive, and treatments without $\mathrm{P}$ a slightly negative time trend.
The responses to $\mathrm{P}$ were considerably greater in the wet than in the dry seasons and greater when $\mathrm{N}$ was applied than when no $\mathrm{N}$ was applied. In all cases the responses to $\mathrm{P}$ increased with time.

\section{Nutrient use efficiency and soil available nutrients}

The nutrient uptake data of Table 3 point to very low $\mathrm{P}$ in the crops receiving no fertilizer P. Although the number of uptake data in Table 3 is very limited, and the treatments only partly coincide with the most appropriate treatments for the estimation of PhEmax (Table 2), the maximum ratios of yield to uptake for $\mathrm{N}, \mathrm{P}$ and $\mathrm{K}$ were calculated, using the most suitable of the available treatments (Table 4, Part A). The value for PhEPmax is the average of 1053 and $1134 \mathrm{~kg}$ grain per $\mathrm{kg} \mathrm{P}$ taken up. These numbers are far outside the established range (Witt et al. 1999) given in Table 1. Therefore it was decided to use for the estimation of soil available $\mathrm{P}$ (SAP) a rounded value of $1000 \mathrm{~kg} \mathrm{~kg}^{-1}$ as maximum PhEP for rice. Maximum PhEN of 75 in Table 4 is between PhENmed and PhENmax in Table 1. Also PhEK of 92 in Table 4 lies between PhEKmed and PhEKmax in Table 1. It is concluded that $\mathrm{P}$ was extremely diluted in the rice crop in the Mekong trial, but $\mathrm{N}$ and $\mathrm{K}$ were not. The strong response to $\mathrm{P}$ mentioned above is in line with these findings.

In Part B of Table 4, the uptakes of N, P and K from the soil are calculated by dividing the yields by the rounded PhEmax. This was done for the treatments that would give maximum uptake of the concerning nutrient from the soil. The uptake from the soil in these treatments may then be considered as a good approximation of the available amount in the Mekong soil (MSA). The MSA data in $\mathrm{kgha}^{-1}$ were divided by the conversion factors for rice, presented in Table 1, to convert them into MSA data in $\mathrm{kCNE}$ $\mathrm{ha}^{-1}$. Next, the MSA's of N, P and K were expressed in $\%$ of the $\mathrm{kCNE}$ sum.

In Table 4 Part $\mathrm{C}$, the apparent maximum recovery fractions of fertilizer nutrients were calculated using the differences among the indicated treatments. The calculated $\mathrm{N}$ and $\mathrm{K}$ recovery fractions are low and point to losses. The REC value for $\mathrm{P}(0.3)$ is high and is considered to be a result of recovery from recently applied as well as from residual fertilizer P, which agrees with the increasing responses to fertilizer $\mathrm{P}$ discussed above. Also the original authors mention 
Table 3 Mekong. Rice grain yields (averages of 8 years) in wet and in dry season, and yields and total nutrient uptake of some treatments in the last season, 1993/94 dry (Tan et al. 1995)

\begin{tabular}{|c|c|c|c|c|c|c|}
\hline \multirow[t]{2}{*}{ Treatment } & \multicolumn{3}{|c|}{ Grain yield, $\mathrm{t}$ ha- ${ }^{1}$} & \multicolumn{3}{|c|}{ Uptake in $1993 / 94, \mathrm{kgha}^{-1}$} \\
\hline & Wet & Dry & 1993/94 Dry & $\mathrm{N}$ & $\mathrm{P}$ & $\mathrm{K}$ \\
\hline Control & 2.08 & 3.36 & 3.89 & 53.6 & 4.92 & 58.2 \\
\hline $\mathrm{N}$ & 2.23 & 4.07 & 4.99 & 77.2 & 4.74 & 64.9 \\
\hline $\mathrm{P}$ & 3.15 & 3.70 & & & & \\
\hline $\mathrm{K}$ & 1.99 & 3.46 & & & & \\
\hline NP & 4.12 & 4.89 & 5.92 & 85.9 & 9.35 & 64.6 \\
\hline NK & 2.24 & 4.01 & 4.99 & 73.9 & 4.4 & 71.2 \\
\hline PK & 3.11 & 3.75 & & & & \\
\hline NPK & 4.27 & 4.97 & 5.92 & 84.8 & 10.31 & 74.1 \\
\hline
\end{tabular}

such an effect (Tan et al. 1995). According to Eq. 1, the cumulative recovery $\left(\mathrm{REC}_{\mathrm{nt}}\right)$ is 0.33 for $n=16$ when q is set at the standard value of 0.7 (Wolf et al. 1987). This is so close to 0.3 that it was decided to stick to the standard value of 0.1 for $\mathrm{REC}_{1}$ in the calculations of Table 4 Part D and E.

In Part D of Table 4, the whole input of nutrients in Mekong (MWI) is expressed in $\mathrm{kgha}^{-1}, \mathrm{kCNE} \mathrm{ha}{ }^{-1}$, and in percentages of the kCNE sum. Next the input of available nutrients (MIA) is calculated, and MA, the sum of MSA and MIA. The calculated NPK compositions of MSA, MWI, MIA and MA are shown in Fig. 3.

Also shown are MTIA and MTWI, which are calculated in Table 4 Part E, following the procedure of Eqs. 3, 4 and 5.

NPK factorial trial on a former sea bottom in the Netherlands

\section{Yields and responses to $N, P$ and $K$}

Average dry-matter yields of the harvested crop components are shown in Table 5. It is obvious that only $\mathrm{N}$ had a strong effect on yield. The effect of $\mathrm{P}$ was more evident for sugar-beet, potatoes and maize than for wheat and barley. The calculated effect of $\mathrm{K}$ always had a negative sign, but was insignificant.

To follow the crop yields in the six successive rotations, rotation means were calculated. The results of treatments with and without $\mathrm{K}$ were averaged as the response to $\mathrm{K}$ was absent. The mean of the yields of a crop obtained with the treatments NP and NPK in the first rotation was set at $100 \%$. Other yields were calculated as percen- tages of that yield. Next the rotation means were found as the average results of the four crops within a rotation (sugar-beet, spring barley, potatoes, wheat). The six wheat yields consisted of four winter-wheat and two spring-wheat data. The last step was the calculation of the cumulative rotation means. Parabolas through the origin gave good fits (Fig. 4). The rotation means increased over time (positive sign of quadratic terms) for the treatments with $\mathrm{N}$, and decreased (negative sign of quadratic terms) for the treatments without $\mathrm{N}$. Responses to $\mathrm{P}$ were not visible until rotation 3 or 4 .

\section{Treatment effects on nutrient uptake and soil available nutrients}

In 1994 and 1998 grains and straw of spring barley, and in 1999 roots and leaves of sugar-beet were analyzed for $\mathrm{N}, \mathrm{P}$ and $\mathrm{K}$, and the nutrient uptake was calculated. The uptake of $\mathrm{N}$, but also the uptakes of $\mathrm{P}$ and $\mathrm{K}$, increased strongly with $\mathrm{N}$ application (Table 6 Part A). This indicates that considerable parts of soil available $\mathrm{P}$ and $\mathrm{K}$ were not used by the crops when no $\mathrm{N}$ was applied. Application of $\mathrm{P}$ stimulated the uptake of P. Application of K had some effect on K uptake but the application rate was small compared to the uptake of K from the soil alone. In 1998 the K uptake by barley from the soil alone was less than in 1994. This and the increasing $\mathrm{K}$ effect on $\mathrm{K}$ uptake could point to a gradual lowering of soil available $\mathrm{K}$. Nevertheless, K uptake by sugar-beet in 1999 in the $\mathrm{K} 0$ treatments was still great.

The maximum nutrient uptake from the soil alone was calculated as a proxy of the available soil supply (FSA). The percentages of $\mathrm{N}, \mathrm{P}$ and $\mathrm{K}$ in the CNE 

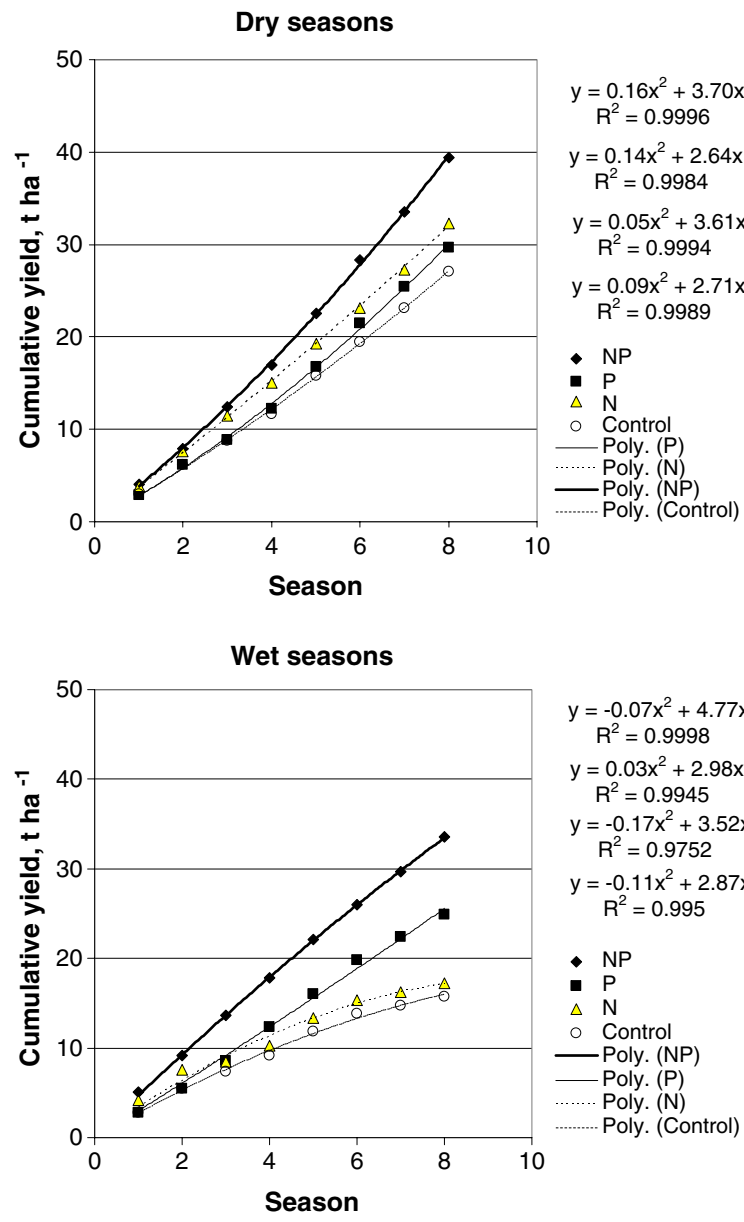

$y=-0.07 x^{2}+4.77 x$ $\mathrm{R}^{2}=0.9998$ $y=0.03 x^{2}+2.98 x$ $\mathrm{R}^{2}=0.9945$ $y=-0.17 x^{2}+3.52 x$ $R^{2}=0.9752$

$y=-0.11 x^{2}+2.87 x$ $\mathrm{R}^{2}=0.995$

\section{- NP}

- $\mathrm{P}$ - Control Poly. (NP)

Poly. (P) -..... Poly. (N) -..... Poly. (Control)

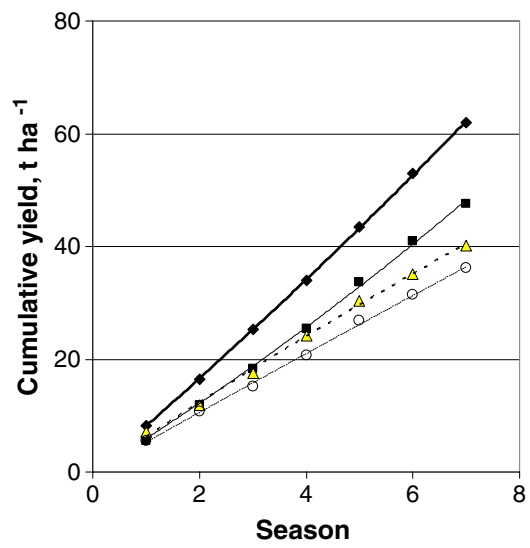

$y=0.12 x^{2}+8.06 x$ $R^{2}=0.9999$

$y=0.16 x^{2}+5.79 x$ $\mathrm{R}^{2}=0.9985$

$y=-0.08 x^{2}+6.33 x$ $R^{2}=0.9975$

$y=-0.02 x^{2}+5.32 x$ $R^{2}=0.9985$

- NP

- $\mathrm{P}$

$\checkmark$ Control Poly. (NP) Poly. (P) .... Poly. (N) ....... Poly. (Control)

Fig. 2 Mekong. Course of cumulative rice yields in dry (top), wet (middle), and dry and wet (bottom) seasons together. NP, P, $\mathrm{N}$ and control are averages of these treatments with and without $\mathrm{K}$. Regression equations are in the same order as the legend sum of FSA point to low N, very high $\mathrm{K}$ and medium $\mathrm{P}$ in the soil (Table 6 Part B). The N, P and $\mathrm{K}$ uptakes by control crops (FU 0-0-0), however, are rather well balanced, except for sugar-beet where $\mathrm{N}$ is still low (Table 6 Part C). The crops did not take up the nutrients in proportion to their supplies.

With the data of FSA (Table 6 Part B) and fertilizer recovery fractions of 0.9 for $\mathrm{N}$ and $\mathrm{K}$ and of 0.1 for $\mathrm{P}$ (from unpublished reports), the NPK compositions of target inputs (FTIA and FTWI) for spring barley were calculated in a similar way as for rice in Table 4, following the procedures of Eqs. 3, 4 and 5. For P, REC was estimated at 0.3 (unpublished reports). Because this represents a cumulative recovery fraction, the standard first season recovery fraction of 0.1 was used to calculate the required $\mathrm{P}$ input. The points of FTIA and FTWI are shown in Fig. 5, together with the compositions of FSA and the NPK input (FIA and FWI) used for spring barley in the long-term experiment.

\section{Discussion}

NPK factorial trial for rice monoculture in the Mekong River Delta of Viet Nam

\section{Differences between dry and wet season in Mekong}

In Mekong, the limiting growth factor obviously was $\mathrm{P}$, and the application of $\mathrm{P}$ in the experiment was too low, especially in the wet season. The better crop growth in the dry season is considered a result of more irradiation and hence higher potential yield, and of a direct after-effect of the natural flooding between the wet and dry seasons. Apparently the natural flood was adding $\mathrm{P}$ to the soil, as mentioned by the authors (Tan et al. 1995). The question arises why the crops did not make use of that flood $\mathrm{P}$ during the wet season. The cause of declining rice yields and the reversal of this decline at the International Rice Research Institute (IRRI) have been ascribed to $\mathrm{N}$ deficiency and improvement of $\mathrm{N}$ management, respectively (Dobermann et al. 2000). It is, however, difficult to understand how poor $\mathrm{N}$ management could be the cause of the low $\mathrm{P}$ availability in the wet seasons. When $\mathrm{P}$ was applied, the response to $\mathrm{N}$ was similar in the wet and the dry seasons (Table 3, NP-P; NPK-PK). Therefore the difference between the dry 
Table 4 Mekong. Estimation of: A. Maximum physiological nutrient use efficiency (PhEmax). B. Soil supply of available nutrients (MSA) in Dry season 1. C. Maximum recovery fraction (RECmax) of fertilizer nutrients. D. NPK composition of whole input (MWI), input of available NPK (MIA), and of total supplies of available NPK (MA). E. Amounts of available nutrients (TA) for target yield, and corresponding input of available nutrients (TIA) and whole input (TWI)

${ }^{\text {a }}$ Yield from Tan et al. 1995

b $\mathrm{CF}=$ conversion factor for rice. See Table 1

c The estimated value of 0.3 refers to a cumulative recovery after 16 applications of $P$. As a cumulative recovery fraction of 0.33 corresponds to a first year recovery fraction (REC) of 0.1 , which is used in Parts $\mathrm{D}$ and $\mathrm{E}$

${ }^{\mathrm{d}}$ PhEmed $=$ medium physiological efficiency. See Table 1

\begin{tabular}{|c|c|c|c|}
\hline & $\mathrm{N}$ & $\mathrm{P}$ & K \\
\hline \multicolumn{4}{|l|}{ A. PhEmax } \\
\hline $\begin{array}{l}\text { Treatments for estimation PhEmax } \\
\text { in Table } 3\end{array}$ & Control & $\mathrm{N}, \mathrm{NK}$ & $\mathrm{NP}$ \\
\hline Calculated PhEmax (= Y/U), $\mathrm{kgkg}^{-1}$ & 73 & 1093 & 92 \\
\hline Rounded PhEmax (see text), $\mathrm{kgkg}^{-1}$ & 75 & 1000 & 92 \\
\hline \multicolumn{4}{|l|}{ B. SA in Dry season 1} \\
\hline Treatments for estimation MSA & $\mathrm{P}, \mathrm{PK}$ & $\mathrm{N}, \mathrm{NK}$ & $\mathrm{NP}$ \\
\hline $\operatorname{Yield}^{\mathrm{a}}(\mathrm{Y}), \mathrm{t} \mathrm{ha}^{-1}$ & 2.89 & 3.82 & 4.01 \\
\hline $\begin{array}{l}\text { Estimated MSA, } \mathrm{kgha}^{-1} \\
(=1000 \cdot \mathrm{Y} / \mathrm{PhEmax})\end{array}$ & 38.5 & 3.8 & 43.6 \\
\hline $\begin{array}{l}\text { Estimated MSA, kCNE/ha } \\
\left(=\mathrm{SA} / \mathrm{CF}^{\mathrm{b}}\right)\end{array}$ & 38.5 & 23.8 & 47.9 \\
\hline Proportions, $\%$ of sum of $110.8 \mathrm{kCNE}$ & 35 & 21 & 44 \\
\hline \multicolumn{4}{|l|}{ C. RECmax } \\
\hline $\begin{array}{l}\text { Treatments for estimation REC } \\
\text { in Table } 3\end{array}$ & NP-P & NP-N, NPK-NK & NPK-NP \\
\hline Rounded estimated REC, $\mathrm{kgkg}^{-1}$ & 0.35 & $0.30^{\mathrm{c}} ; 0.1$ & 0.4 \\
\hline \multicolumn{4}{|l|}{$\begin{array}{l}\text { D. Composition of MWI, MIA } \\
\text { and MA }\end{array}$} \\
\hline MWI, $\mathrm{kgha}^{-1}$ (Tan et al. 1995) & 80 & 17.5 & 25 \\
\hline MWI, kCNE ha ${ }^{-1}\left(=\mathrm{MWI} / \mathrm{CF}^{\mathrm{b}}\right)$ & 80 & 105 & 28 \\
\hline MWI, $\%$ of $213 \mathrm{kCNE} \mathrm{ha}^{-1}$ & 38 & 49 & 13 \\
\hline MIA, $\mathrm{kCNE} \mathrm{ha}{ }^{-1}(=\mathrm{MWI} \cdot \mathrm{RECmax})$ & 28.0 & 10.5 & 11.0 \\
\hline MIA, $\%$ of $49.5 \mathrm{kCNE} \mathrm{ha}^{-1}$ & 57 & 21 & 22 \\
\hline $\mathrm{MA}, \mathrm{kCNE} \mathrm{ha}{ }^{-1}(=\mathrm{MSA}+\mathrm{MIA})$ & 67 & 33 & 59 \\
\hline $\mathrm{MA}, \%$ of $159 \mathrm{kCNE} \mathrm{ha}{ }^{-1}$ & 42 & 21 & 37 \\
\hline \multicolumn{4}{|l|}{$\begin{array}{l}\text { E. Estimation of TA, TIA and TWI } \\
\text { for a target yield (TY) of } 5 \mathrm{tha}^{-1}\end{array}$} \\
\hline TA, $\mathrm{kgha}^{-1}(=\mathrm{TY} / 0.91 \cdot \mathrm{PhEmed})^{\mathrm{d}}$ & 80 & 13.3 & 73 \\
\hline $\mathrm{TA}, \mathrm{kCNE} \mathrm{ha}{ }^{-1}\left(=\mathrm{TA} / \mathrm{CF}^{\mathrm{b}}\right)$ & 80 & 80 & 80 \\
\hline TIA, $\mathrm{kgha}^{-1}(=$ TA-MSA) & 41 & 9.5 & 29 \\
\hline TIA, kCNE ha ${ }^{-1}(=$ TA-MSA) & 41 & 57 & 32 \\
\hline TIA, $\%$ of $130 \mathrm{kCNE} \mathrm{ha}{ }^{-1}$ & 32 & 44 & 25 \\
\hline TWI, $\mathrm{kgha}^{-1}(=$ TIA/REC $)$ & 118 & 95 & 73 \\
\hline TWI, kCNE ha ${ }^{-1}(=$ TIA/REC $)$ & 118 & 568 & 80 \\
\hline TWI,\% of $766 \mathrm{kCNE} \mathrm{ha}^{-1}$ & 15 & 74 & 10 \\
\hline
\end{tabular}

and the wet season likely was caused by a difference in $\mathrm{P}$ availability. The wet season instantly followed the dry season while the dry season started only after 3 months of natural flooding. During growth seasons the labile pool of $\mathrm{P}$, and also that of $\mathrm{K}$, gets more or less depleted, and in between two growing periods there must be sufficient time for the relevant chemical processes to restore these labile pools. For K, it has been shown that the length of the fallow period between two successive seasons is crucial for the replenishment of the labile pool in the Mekong delta (Hoa 2003; Hoa et al. 2006). It is hypothesized that the periods between the dry and wet seasons in the present long-term experiment were too short for replenishment of the labile $\mathrm{P}$ pool. Between the wet and the next dry season there was considerably more time for replenishment of the labile pool, so that treatments $\mathrm{N}$ and $\mathrm{NK}$ in the dry season could have similar yields as treatments NP and NPK, respectively, in the wet season (see Table 3, Fig. 2). For 


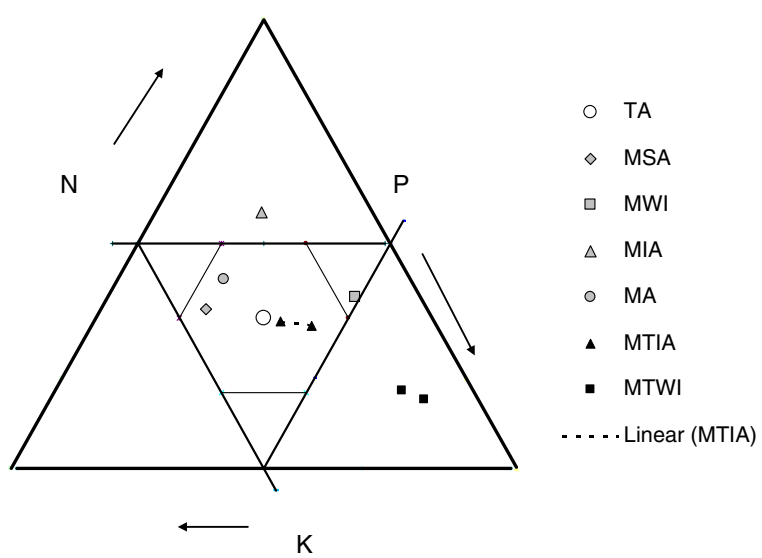

Fig. 3 Mekong. NPK compositions of soil available nutrients (MSA), whole input (MWI) and input of available nutrients (MIA), and the sum of available nutrients from input and soil (MA) in Dry season 1, as calculated from data in Tables 3 and 4. TA is the composition of the target quantity of available nutrients $(\mathrm{TA}=\mathrm{SA}+\mathrm{IA})$. The points of MTIA and MTWI refer to target yields of 5 (right) and 10 (left) $\mathrm{t} \mathrm{ha}^{-1}$

sustainable rice production, $\mathrm{P}$ application at the beginning of the wet season is essential.

\section{Need for chemical crop analysis}

The continuation of the experimental treatments during 8 years has worsened the situation of severe $\mathrm{P}$ deficiency. Could this have been foreseen? In retrospect the answer is yes, when nutrient uptake had been assessed and the supply of soil available (MSA) had been estimated in the first experimental year. Then for any target yield, the compositions of MTIA and MTWI could have been calculated with Eqs. 4 and 5, as was done in Table 4 Part E. The points and lines for MTIA and MTWI shown in Fig. 3 illustrate once more that the applications in the longterm experiment were far too low in P.

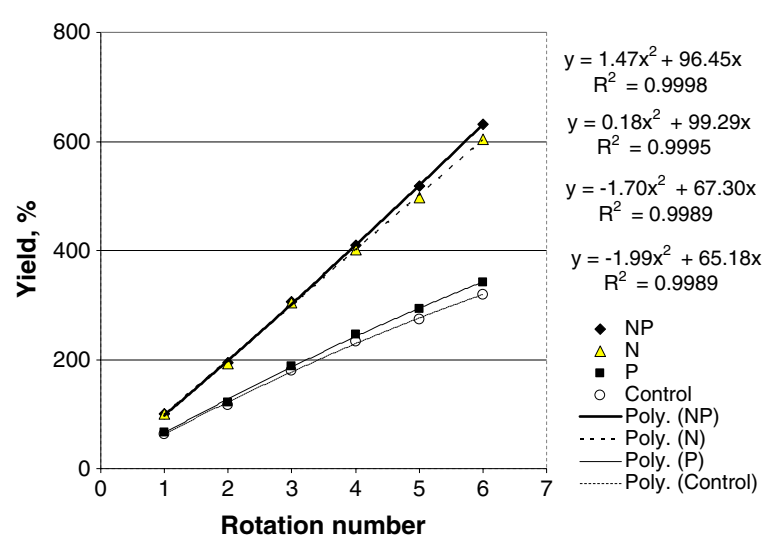

Fig. 4 Flevoland. Course of cumulative rotation yield averages. NP, P, N and control are averages of these treatments with and without $\mathrm{K}$. The yield of the NP treatment in Rotation 1 was set at $100 \%$ and other yields were calculated as percentages of that yield. Regression equations are in the same order as the legend

NPK factorial trial on a former sea bottom in Flevoland, the Netherlands

\section{$N: P: K$ proportions}

Apparently the crops did not take up the nutrients in proportion to their supplies, but selectively according to their needs (Table 6). The percentage of $\mathrm{N}$ in the $\mathrm{kCNE}$ sum was in the control crop about twice as high as in FSA, while the percentage of $\mathrm{K}$ in the control crop was about half as high as that in FSA. The percentage of $\mathrm{P}$ in the CNE sum was a little higher in the control crop than in FSA. As a consequence, the NPK composition of the control crop did not indicate that the nutrient supply by the soil was out of balance and, hence, had limited value as a diagnostic tool for recommendations on nutrient inputs.

According to calculations of FTIA there is no need at all to apply $\mathrm{K}$, as long as the target grain yield of
Table 5 Flevoland. Number of harvests of six crops, average dry-matter yields of indicated crop components, and average effects on yield by application of $\mathrm{N}, \mathrm{P}$ and $\mathrm{K}$

\begin{tabular}{lllllll}
\hline Treatment & \multicolumn{5}{l}{ Crops and harvested crop component. All yields in t ha-1 } \\
\cline { 2 - 7 } Component & $\begin{array}{l}\text { Sugar-beet } \\
\text { Root }\end{array}$ & $\begin{array}{l}\text { Spring barley } \\
\text { Grain }\end{array}$ & $\begin{array}{l}\text { Potatoes } \\
\text { Tuber }\end{array}$ & $\begin{array}{l}\text { Winter wheat } \\
\text { Grain }\end{array}$ & $\begin{array}{l}\text { Spring wheat } \\
\text { Grain }\end{array}$ & $\begin{array}{l}\text { Maize } \\
\text { Total }\end{array}$ \\
\cline { 2 - 7 } Number & 5 & 6 & 6 & 4 & 2 & 2 \\
Average yield & 11.25 & 4.21 & 10.08 & 5.41 & 5.06 & 8.79 \\
N effect & 6.22 & 2.88 & 4.84 & 3.47 & 3.83 & 3.61 \\
P effect & 1.17 & 0.25 & 0.93 & -0.06 & 0.27 & 1.38 \\
K effect & -0.53 & -0.10 & -0.07 & -0.14 & -0.20 & -0.04 \\
\hline
\end{tabular}


Table 6 Flevoland. Spring barley and sugar-beet. A. Uptake of $\mathrm{N}, \mathrm{P}$ and $\mathrm{K}$, averaged across all treatments, and average effects of $\mathrm{N}, \mathrm{P}$ and $\mathrm{K}$ application on uptake $\left(\mathrm{kgha}^{-1}\right)$ in the years indicated. B. Maximum nutrient uptake from the soil alone (FSA), expressed in $\mathrm{kgha}^{-1}, \mathrm{kCNE} \mathrm{ha}{ }^{-1}$, and \% of sum of
kCNE. C. Uptake in the control treatment. Uptake refers to total crop (grains + straw; roots + leaves). Application rates for spring barley: 53.5 and $107 \mathrm{kgN} \mathrm{ha}^{-1}, 25.1 \mathrm{kgP}^{-1}, 41.5 \mathrm{kgK}$ $\mathrm{ha}^{-1}$; for sugar-beet: 100 and $200 \mathrm{kgN} \mathrm{ha}^{-1}, 65.5 \mathrm{kgP} \mathrm{ha}^{-1}$, $62.2 \mathrm{kgK} \mathrm{ha}{ }^{-1}$

\begin{tabular}{|c|c|c|c|c|c|c|c|c|c|}
\hline & \multicolumn{3}{|c|}{ Spring barley 1994} & \multicolumn{3}{|c|}{ Spring barley 1998} & \multicolumn{3}{|c|}{ Sugar-beet 1999} \\
\hline & $\mathrm{N}$ & $\mathrm{P}$ & $\mathrm{K}$ & $\mathrm{N}$ & $\mathrm{P}$ & $\mathrm{K}$ & $\mathrm{N}$ & $\mathrm{P}$ & $\mathrm{K}$ \\
\hline & \multicolumn{9}{|c|}{ A. Average uptake and treatment effects } \\
\hline Average & 63 & 19 & 96 & 82 & 22 & 86 & 169 & 27 & 309 \\
\hline $\mathrm{N}$ effect ${ }^{\mathrm{a}}$ & 58 & 16 & 100 & 69 & 15 & 75 & 154 & 11 & 217 \\
\hline$P$ effect & 7 & 6 & 13 & -1 & 3 & 2 & -2 & 13 & -14 \\
\hline $\mathrm{K}$ effect & -3 & -1 & 4 & 0 & 0 & 16 & 3 & -1 & 35 \\
\hline Unit & \multicolumn{9}{|c|}{ B. Maximum uptake from soil alone (FSA) } \\
\hline $\operatorname{kgha}^{-1}$ & 28 & 24 & 166 & 40 & 25 & 108 & 80 & 28 & 460 \\
\hline $\mathrm{kCNE} \mathrm{ha}^{-1}$ & 28 & 80 & 166 & 40 & 83 & 108 & 80 & 154 & 307 \\
\hline \multirow[t]{2}{*}{$\%$ of sum } & 10 & 29 & 61 & 17 & 36 & 47 & 14 & 32 & 54 \\
\hline & \multicolumn{9}{|c|}{ C. Control uptake (FU 0-0-0) } \\
\hline $\mathrm{kgha}^{-1}$ & 20 & 7 & 24 & 34 & 11 & 31 & 58 & 16 & 137 \\
\hline $\mathrm{kCNE} \mathrm{ha}^{-1}$ & 20 & 24 & 24 & 34 & 37 & 31 & 58 & 107 & 91 \\
\hline$\%$ of sum & 30 & 35 & 35 & 33 & 36 & 31 & 23 & 42 & 36 \\
\hline
\end{tabular}

a Average of $\mathrm{N} 1$ and $\mathrm{N} 2$ effects

spring barley is less than $9.1 \mathrm{t} \mathrm{ha}^{-1}$. Comparison of the point of FIA with those of FTIA in Fig. 5 shows that the applications in the long-term experiment were too low in $\mathrm{N}$ and $\mathrm{P}$ and too high in $\mathrm{K}$.

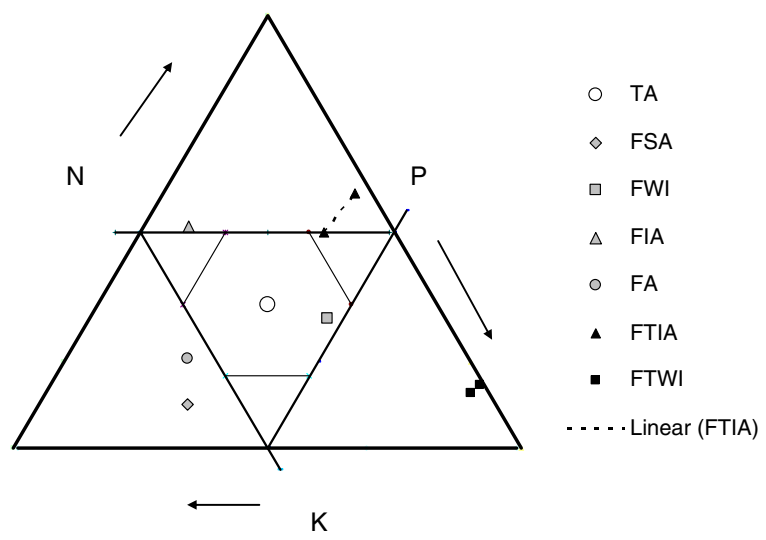

Fig. 5 NPK compositions of soil available nutrients in Flevoland (FSA), whole input (FWI) and input of available nutrients (FIA), and the sum of available nutrients from input and soil (FA) in 1994, as calculated from data in Table 6. TA is the composition of the target quantity of available nutrients $(\mathrm{TA}=\mathrm{SA}+\mathrm{IA})$. The points and lines of FTIA and FTWI refer to target yields of 9.5 (right) and 12 (left) $\mathrm{t} \mathrm{ha}^{-1}$

\section{Sustained soil productivity in Flevoland}

The above results suggest that there is no problem in sustaining soil productivity in Flevoland, as far as it concerns NPK. The recovery fraction of fertilizer $\mathrm{N}$ is high because there is no leaching during crop growth and any leached nutrients may return to the rooting zone by capillary rise of groundwater in this polder. The uptake of $\mathrm{K}$ from the soil simply follows crop growth which in its turn is a function of $\mathrm{N}$ and $\mathrm{P}$ uptake from soil and input. Hence, there is no need to apply any $\mathrm{K}$, and it may be expected that the soil supply of $\mathrm{K}$ is more than sufficient for some more decades. If the recommendations for FTIA and FTWI are followed, it is to be expected that SA in Flevoland gradually shifts from the present position of FSA (Fig. 5) to that of SA at ISF (Fig. 1). Once that has happened, replacement input of NPK will be sufficient for sustained soil productivity, because nutrients are hardly lost in Flevoland.

\section{Nutrient supply from soil and fertilizer in Flevoland}

The original aim of the experiment in Flevoland was to find how long it would take before inputs of $\mathrm{N}, \mathrm{P}$ 
and $\mathrm{K}$ would be needed. It was concluded that the soil supply of $\mathrm{P}$ was sufficient for 20 crops (Janssen and Menkveld 1998). In 2002, the last year of the experiment, there was still no need for $\mathrm{K}$ input, i.e. after 43 crops. It is not possible to predict on the basis of the presently available data how long the soil can continue providing sufficient $\mathrm{K}$. Only prolongation of the long-term experiment could have given an answer. It is obvious, however, that the natural situation in this polder can be considered as excellent for crop production. The major reasons are that the soil originally is rich in $\mathrm{P}$ and very rich in $\mathrm{K}$, and that there is no leaching of fertilizer $\mathrm{N}$ during the growing season. Further the subsoil adds to the $\mathrm{N}$ supply in these young polder soils. The apparent recovery of fertilizer $\mathrm{N}$ was close to $100 \%$ in this long-term experiment, which is not exceptional in Flevoland. It was also found in grassland (Lantinga et al. 1999). For wheat an apparent recovery of fertilizer $\mathrm{N}$ of 70 $75 \%$ was found between application rates of 50 and $100 \mathrm{kgN}$ (Spiertz and Ellen 1978); unfortunately no treatment without fertilizer $\mathrm{N}$ was included in their study. The capillary rise of groundwater plus dissolved nutrients contributes to the high $\mathrm{N}$ recovery. The capillary water also makes that crops seldom suffer from drought. In summary: these young polders allow crops to grow without stress if $\mathrm{N}$ and $\mathrm{P}$ are adequately applied. At the experimental site SOC was $16 \mathrm{~g} \mathrm{~kg}^{-1}$ which was considered critical in Kabete (see accompanying paper). There were no indications that $16 \mathrm{~g} \mathrm{~kg}^{-1}$ was too low in Flevoland, although the fraction $<20 \mu \mathrm{m}$ was around $420 \mathrm{gkg}^{-1}$ not much below $473 \mathrm{~g} \mathrm{~kg}^{-1}$ calculated for a soil requiring a SOC of $16 \mathrm{~g} \mathrm{~kg}^{-1}$. Other reasons why soil structure is not at stake, provided not too heavy machinery is used, are that the presence of $\mathrm{CaCO}_{3}$ and the high $\mathrm{pH}$ in Flevoland mitigate the necessity of high SOC for the maintenance of soil structure. Moreover the land is flat and not very prone to erosion.
Comparison of Mekong and Flevoland

The supplies (in kCNE) of available N, P and K of the treatment N1P1K1 were not equal, neither in Mekong nor in Flevoland. As a consequence the points of MA in Fig. 3 and of FA in Fig. 5 are not in the centre of the triangle. The fraction FP of MA was only $22 \%$ (Table 4 Part D), indicating that the nutrient supply from soil and input in this long-term trial was out of balance even for the N1P1K1 treatment in the first dry season.

In Flevoland the relative NPK composition of FA was 21-24-55 (calculation not shown), and the position of FA in Fig. 5 was in the left-hand corner of the triangle far from the centre. Fertilizer $\mathrm{K}$ was applied because it was an experimental treatment in the factorial design. With the knowledge obtained from the trial, however, the conclusion is that $\mathrm{K}$ application in agricultural practice essentially is wastage in this area.

Table 7 shows agronomic nutrient use efficiencies of fertilizer nutrients in the two agroecosystems studied in this paper. Although different crops were used, the values of AE may be compared as both are all cereal crops showing similar relations between grain production and nutrient uptake (Van Keulen and Van Heemst 1982). The low AEKs, in Mekong as well as in Flevoland, are due to high availability of $\mathrm{K}$ (SAK) in both soils. Flevoland has the highest AEN which is ascribed to the high recovery of fertilizer N; AEP changed from 0 initially to more than 20 in the later rotations. In Mekong, the high AEP is caused by the very high physiological $\mathrm{P}$ use efficiency, which in itself is a reaction to the extremely low $\mathrm{P}$ availability in the soil. In both locations, Mekong and Flevoland, the apparent recovery of fertilizer $\mathrm{P}$ was as high as 0.3 , and in both cases this could be understood as the result of residual recovery of fertilizer $P$. It reveals the
Table 7 Comparison of the agronomic nutrient use efficiencies ( $\mathrm{kg}$ yield increase per $\mathrm{kg}$ of applied fertilizer nutrient) in the two agroecosystems studied

\begin{tabular}{llll}
\hline \multirow{2}{*}{ Agronomic nutrient use efficiencies (AE) } & \multicolumn{2}{l}{ Mekong, rice } & \multirow{2}{*}{ Flevoland, spring barley } \\
\cline { 2 - 3 } & Wet season & Dry season & \\
\hline AEN & 13 & 15 & 26 to 60 \\
AEP & 112 & 51 & 0 to 24 \\
AEK & 3 & 0 & -8 to 4 \\
\hline
\end{tabular}


increasing role of $\mathrm{P}$ on improving yields once the application of $\mathrm{P}$ has begun.

Improper NPK ratios of nutrient inputs lead to wasting of nutrients and hence to damage to the environment. This likely has contributed to losses of $\mathrm{N}$ and $\mathrm{K}$ in the Mekong study where in relation to $\mathrm{P}$ too much $\mathrm{N}$ and $\mathrm{K}$ were applied.

\section{Balanced N:P:K proportions and factorial designs}

Chemical crop analysis proved very helpful in understanding the crop performance in Mekong and Flevoland. The values of the soil supplies of available N, P and K (SAN, SAP, SAK) could be found thanks to the factorial designs of the trials. The interpretation of the chemical data was facilitated by conversion of mass units $(\mathrm{kg})$ into crop nutrient equivalents ( $\mathrm{kCNE}$ ) and by the use of NPK triangles, thus demonstrating the value of the CNE concept. It was a pity that crops had been analyzed late and not in the beginning of the experiments. The design of the trial in Mekong could have been more efficient if already in the first season crops would have been analyzed for N, P and $\mathrm{K}$, by preference in both the dry and wet season and in all experimental treatments. The low $\mathrm{P}$ availability, especially in the wet season, would have shown up clearly in the percentage SAP takes in the sum of SAN, SAP, and SAK, and the design of the experiment could have been redressed on time. $\mathrm{P}$ uptake in control treatment does not give that information. In the Flevoland experiment, the excessive amounts of soil available $\mathrm{K}$ did not show up in the analysis of the crop of the control treatment. Because of the selective nutrient uptake by crops, the proportions of NPK in the crop are considerably different than the proportions of NPK in the soil supplies of available NPK. To find the latter, minus one experiments would suffice as appears from the treatments recommended for SA in Table 2, but factorials give information on PhEmin as well, and the information is statistically more reliable as was shown already in the sixties (Le Mare 1963).

The role of balanced N:P:K proportions seems to remain greatly underrated in soil fertility and plant nutrition research, notwithstanding already half a century ago several publications were issued emphasizing the importance of equilibrated plant nutrition, to be understood as plant nutrition with optimum ratios between $\mathrm{N}$, $\mathrm{P}, \mathrm{K}$ and other nutrients (Homès 1961; Homès and Verschoor 1966; Beaufils 1971). Despite this recognition of the significance of nutrient ratios, studies on ratios continued to be less popular than research on individual nutrients. In this paper the problem of handling ratios of three nutrients at a same time was solved by application of the concept of crop nutrient equivalents (CNE), and the use of NPK triangles. It made it easy to show and calculate in what direction nutrient inputs should be changed to attain balanced nutrition and by that minimum nutrient wastes. Balanced NPK proportions lead to maximum nutrient use efficiency and thus saves farmers' budgets and environment.

\section{Conclusions}

The cause of non-sustainability in the Mekong delta was unbalanced crop nutrition created by too low $\mathrm{P}$ applications and decreasing soil $\mathrm{P}$ availability in the wet seasons. It is hypothesized that the latter was a result of too short periods between the dry and wet cropping seasons for the replenishment of the labile pool of soil P. Retarded crop growth resulting from $\mathrm{P}$ deficiency likely contributed to losses of $\mathrm{N}$ and $\mathrm{K}$. Assessment of nutrient uptake in the beginning would have offered early warnings of unbalanced plant nutrition in both long-term experiments, and of losses of $\mathrm{N}$ and $\mathrm{K}$ in Mekong.

Unsustained soil productivity will not become an issue in Flevoland, as long as $\mathrm{N}$ and $\mathrm{P}$ are applied. For the time being there is no need to apply $\mathrm{K}$.

The graphs of cumulative yields versus time simplified the illustration of treatment effects and time trends in the long-term experiments. The concept of crop nutrient equivalents and the related NPK triangles proved helpful tools in the valuation of chemical crop and soil analysis, and in designing systems for balanced crop nutrition and thus for sustained soil productivity. In both locations, Mekong and Flevoland, the apparent recovery of fertilizer $\mathrm{P}$ was as high as 0.3 , and in both cases this could be understood as the result of residual recovery of fertilizer $P$, that could be assessed with a simple equation for the residual $\mathrm{P}$ effect.

Open Access This article is distributed under the terms of the Creative Commons Attribution Noncommercial License which permits any noncommercial use, distribution, and reproduction in any medium, provided the original author(s) and source are credited. 


\section{Appendix}

One straight line through SA, TA TIA, in case of balanced NPK supplies

\section{Introductory remarks and notations}

If the ratios of soil available nutrients (SA) to the amounts of available nutrients required for target yield (TA), so the ratios of SAN/TAN, SAP/TAP and SAK/TAK are q, $r$ and s, respectively, it follows from Eq. 4 that the ratios of TIAN/TAN, TIAP/TAP and TIAK/TAK are (1-q), (1-r) and (1-s). The proportions of SAN : SAP : SAK are $q \cdot$ TAN $: r \cdot$ TAP $: s$ • TAK, which equals $q: r: s$ at balanced nutrient supply where TAN $=$ TAP $=$ TAK if expressed in kCNE. Similarly, the proportions of TIAN : TIAP : TIAK are (1-q) · TAN : (1-r) · TAP : (1-s) · TAK, or (1-q) : (1-r) : (1-s). Hence, if expressed in percentages, FNS, FPS, FKS, the N, P and K fractions of SA, are: $100 \cdot \mathrm{q} /(\mathrm{q}+\mathrm{r}+\mathrm{s}), 100 \cdot \mathrm{r} /(\mathrm{q}+\mathrm{r}+\mathrm{s})$, and $100 \cdot \mathrm{s} /(\mathrm{q}+\mathrm{r}+\mathrm{s})$, respectively. The sum of $(\mathrm{q}+\mathrm{r}+\mathrm{s})$ henceforth is denoted by QRS, so FNS, FPS, FKS are $100 \mathrm{q} /$ QRS, 100r/QRS, and $100 \mathrm{~s} / \mathrm{QRS}$. It follows that the N, P and K fractions of TIA (FNTI, FPTI, FKTI), are: $100 \cdot(1-\mathrm{q}) /$ (3-QRS), $100 \cdot(1-r) /(3-Q R S)$, and $100 \cdot(1-\mathrm{s}) /(3-\mathrm{QRS})$, if expressed in percentages.

The soil supplies of available nutrients seldom are equal for $\mathrm{N}, \mathrm{P}$ and $\mathrm{K}$. To arrive at balanced nutrient supplies by soil and input, first the most limiting nutrient is applied till the sum of SA+IA of that nutrient has reached the SA level of the second most limiting nutrient. Next these two limiting nutrients are applied till the level of the highest SA. From there onwards all three nutrients are applied in balanced proportions. As a consequence, the NPK composition of nutrient inputs (FNI, FPI and FKI) required for balanced nutrient supplies depend on the level of the target yield (TY). For a given SA, the values of $\mathrm{q}, \mathrm{r}$ and $\mathrm{s}$ become smaller, and those of (1-q), (1-r) and (1-s) become larger with increasing TY and TA. At very large TY, the NPK proportions of TIA approach 1:1:1.

\section{Mathematical prove that SA, TA, and TIA lie on one straight line}

In the NPK triangle, the compositions of TIA are found on the extension of the straight line through the points of SA and the centre of the triangle (Fig. 1). To prove this, it is convenient to transform (the points of) the triangle into $\mathrm{X}$ and $\mathrm{Y}$ coordinates. If the origin of the $\mathrm{X}-\mathrm{Y}$ diagram corresponds to the $\mathrm{N}, \mathrm{P}$ and $\mathrm{K}$ fractions of 0,0 and $100 \%$, it follows from simple geometry that at any point in the triangle the value along the $\mathrm{Y}$-axis is equal to $\mathrm{SQRT}(3) \cdot 0.5 \cdot \mathrm{FN}$, and that along the $\mathrm{X}$-axis to $0.5 \cdot(100+\mathrm{FP}-\mathrm{FK})$.

In the $\mathrm{X}-\mathrm{Y}$ diagram, $\mathrm{Y}=\mathrm{B} \cdot \mathrm{X}+\mathrm{C}$ stands for a straight line, and the points of SA, TA and TIA are denoted by $\mathrm{X}_{\mathrm{SA}}, \mathrm{Y}_{\mathrm{SA}} ; \mathrm{X}_{\mathrm{TA}}, \mathrm{Y}_{\mathrm{TA}}$ and $\mathrm{X}_{\mathrm{TIA}}, \mathrm{Y}_{\mathrm{TIA}}$. When these points lie on a same straight line, the slope of the line trough SA and TIA must be equal to the slope of the line trough SA and TA, or

$$
\mathrm{B}_{1}=\left(\mathrm{Y}_{\mathrm{TIA}}-\mathrm{Y}_{\mathrm{SA}}\right) /\left(\mathrm{X}_{\mathrm{TIA}}-\mathrm{X}_{\mathrm{SA}}\right)=\mathrm{B}_{2}=\left(\mathrm{Y}_{\mathrm{TA}}-\mathrm{Y}_{\mathrm{SA}}\right) /\left(\mathrm{X}_{\mathrm{TA}}-\mathrm{X}_{\mathrm{SA}}\right)
$$

The various parts of Eq. A1 can be expressed in $\mathrm{q}, \mathrm{r}$ and $\mathrm{s}$.

$$
\begin{aligned}
& \left(\mathrm{Y}_{\mathrm{TIA}}-\mathrm{Y}_{\mathrm{SA}}\right)=0.5 \cdot \mathrm{SQRT}(3) \cdot(\mathrm{FNI}-\mathrm{FNS}) \\
& =0.5 \cdot \mathrm{SQRT}(3) \cdot\{100 \cdot(1-\mathrm{q}) /(3-\mathrm{QRS})-100 \mathrm{q} / \mathrm{QRS}\} \\
& =0.5 \cdot \operatorname{SQRT}(3) \cdot(100 \mathrm{QRS}-300 \mathrm{q}) /\{(3-\mathrm{QRS}) \cdot \mathrm{QRS}\} \\
& \mathrm{X}_{\mathrm{TIA}}=0.5 \cdot(100+\mathrm{FPI}-\mathrm{FKI})=0.5 \cdot\{100+100 \cdot(1-\mathrm{r}) /(3-\mathrm{QRS})-100 \cdot(1-\mathrm{s}) /(3-\mathrm{QRS})\} \\
& =0.5 \cdot\{(300-100 \mathrm{QRS}+100 \mathrm{~s}-100 \mathrm{r}) /(3-\mathrm{QRS})\} \\
& \mathrm{X}_{\mathrm{SA}}=0.5 \cdot(100+\mathrm{FPS}-\mathrm{FKS})=0.5 \cdot\{100+(100 \mathrm{r} / \mathrm{QRS})-100 \mathrm{~s} /(\mathrm{QRS})\} \\
& =0.5 \cdot(100 \mathrm{QRS}+100 \mathrm{r}-100 \mathrm{~s}) / \mathrm{QRS}
\end{aligned}
$$


After rearranging the difference $\left(\mathrm{X}_{\mathrm{TIA}}-\mathrm{X}_{\mathrm{SA}}\right)$ is found to be:

$\mathrm{X}_{\mathrm{TIA}}-\mathrm{X}_{\mathrm{SA}}=0.5 \cdot\{300 \cdot(\mathrm{s}-\mathrm{r})\} /\{(3-\mathrm{QRS}) \cdot \mathrm{QRS}\}$

Hence, $\mathrm{B}_{1}$, the slope of the line through SA and TIA is:

$[0.5 \cdot \mathrm{SQRT}(3) \cdot(100 \mathrm{QRS}-300 \mathrm{q}) /\{(3-\mathrm{QRS}) \cdot \mathrm{QRS}\}] /[0.5 \cdot\{300 \cdot(\mathrm{s}-\mathrm{r})\} /\{(3-\mathrm{QRS}) \cdot \mathrm{QRS}\}]$

$\mathrm{B}_{1}=\{\operatorname{SQRT}(3) \cdot(3 \mathrm{q}-\mathrm{QRS})\} /\{3 \cdot(\mathrm{r}-\mathrm{s})\}$

The value of $\mathrm{Y}_{\mathrm{TA}}=0.5 \cdot \operatorname{SQRT}(3) \cdot 100 / 3$, and that of $\mathrm{X}_{\mathrm{TA}}$ is 50 . It follows that:

$\mathrm{Y}_{\mathrm{TA}}-\mathrm{Y}_{\mathrm{SA}}=0.5 \cdot \mathrm{SQRT}(3) \cdot(100 / 3-\mathrm{FNS})=0.5 \cdot \mathrm{SQRT}(3) \cdot(100 / 3-100 \mathrm{q} / \mathrm{QRS})$, and

$\mathrm{X}_{\mathrm{TA}}-\mathrm{X}_{\mathrm{SA}}=50-\{0.5 \cdot(100 \mathrm{QRS}+100 \mathrm{r}-100 \mathrm{~s}) / \mathrm{QRS}\}$

So, $\mathrm{B}_{2}$, the slope of the line through SA and TIA is:

$\{0.5 \cdot \operatorname{SQRT}(3) \cdot(100 / 3-100 \mathrm{q} / \mathrm{QRS})\} /[50-\{0.5 \cdot(100 \mathrm{QRS}+100 \mathrm{r}-100 \mathrm{~s}) / \mathrm{QRS}\}]$

$\mathrm{B}_{2}=\{\operatorname{SQRT}(3) \cdot(3 \mathrm{q}-\mathrm{QRS})\} /\{3 \cdot(\mathrm{r}-\mathrm{s})\}$

Because $B_{1}$ in Eq. $A 2$ is equal to $B_{2}$ in Eq. $A 3$, it is concluded that the points of SA, TA and TIA lie on the same straight line.

The intercept of the line in the $\mathrm{X}-\mathrm{Y}$ diagram is:

$\mathrm{C}=\mathrm{Y}-\mathrm{B} \cdot \mathrm{X}$

Substitution $\mathrm{Y}_{\mathrm{TA}}, \mathrm{X}_{\mathrm{TA}}$ and $\mathrm{B} 2$ for $\mathrm{Y}, \mathrm{X}$ and $\mathrm{B}$ in Eq. A4 results in:

$$
\begin{aligned}
\mathrm{C} & =0.5 \cdot \operatorname{SQRT}(3) \cdot 100 / 3-\{\operatorname{SQRT}(3) \cdot(3 \mathrm{q}-\mathrm{QRS})\} /\{3 \cdot(\mathrm{r}-\mathrm{s})\} \cdot 50= \\
& =\{50 / \operatorname{SQRT}(3)\} \cdot\{1-(3 \mathrm{q}--\mathrm{QRS}) /(\mathrm{r}-\mathrm{s})\}=28.86751 \cdot\{1-(3 \mathrm{q}-\mathrm{QRS}) /(\mathrm{r}-\mathrm{s})\}
\end{aligned}
$$

Both regression coefficients, B and C, only depend on $\mathrm{q}, \mathrm{r}$ and s, so on the NPK composition of SA. Because the position of TA is always in the centre of the triangle, it is easily seen in Fig. 1 that only SA determines the position of the line through SA, TA and TIA.

The points of TWI for different target yields also lie on a straight line (Fig. 1). This line, however, does not go through SA and the centre of the triangle. Its position depends on the position of the line for TIA, and on the recovery fractions (REC) of $\mathrm{N}, \mathrm{P}$ and $\mathrm{K}$.

The special case of 'Ideal soil fertility' (ISF)

To keep soil fertility at the same level, nutrient outputs must be compensated for by nutrient inputs. When no nutrients are lost by leaching, volatilization or erosion, the only nutrient outputs are the nutrients in the harvested components (e.g. grain and straw) of a crop producing the target yield. The input required in such conditions is known as 'replacement input'. The crop takes up only a fraction (recovery fraction, REC) of the whole input (WI) of nutrients, thus IU $=\mathrm{REC} \cdot \mathrm{WI}$, where IU is the uptake from input. In case of replacement input, WI $=$ TU by 
definition, and then IU $=\mathrm{REC} \cdot \mathrm{TU}$, and SU must equal $(1-\mathrm{REC}) \cdot \mathrm{TU}$. The corresponding soil fertility was called 'ideal soil fertility' (ISF), and the values of RECN, RECP and RECK for cereal crops were set at 0.8, 0.1, and 0.6, respectively (Janssen and De Willigen 2006).

For balanced nutrition and replacement input, i.e. at ISF, it holds that TUN $=\mathrm{TUP}=\mathrm{TUK}=\mathrm{WIN}=\mathrm{WIP}=\mathrm{WIK}$, when TU and WI are expressed in kCNE. According to QUEFTS calculations, A=1.047 $\cdot \mathrm{U}$ in case of balanced nutrition for each of N, P and $\mathrm{K}$, so also TAN $=$ TAP $=$ TAK at ISF. Hence the centre of the NPK triangle represents the composition of TA, TU and WI at ISF. Also here the points of SA, TA and TIA are on one straight line. The proportions of TIUN : TIUP : TIUK of cereal crops, and also the proportions of TIAN : TIAP : TIAK, are at ISF are equal to RECN : RECP : RECK, so to $0.8: 0.1: 0.6$. This implies that TIAN $=100 \cdot 0.8 /(0.8+0.1+0.6)=53 \%$; TIAP $=7 \%$, and TIAK $=40 \%$ of the sum of TIAN, TIAP and TIAK. Similarly, the proportions of SUN : SUP : SUK and of SAN, SAP and SAK at ISF are equal to $(1-\mathrm{RECN}):(1-\mathrm{RECP}):(1-\mathrm{RECK})=0.2: 0.9: 0.4$, and $\mathrm{SAN}=100 \cdot 0.2 /(0.2+0.9+0.4)=13 \% ; \mathrm{SAP}=60 \%$, and $\mathrm{SAK}=27 \%$ of the sum of SAN, SAP and SAK. Figure 1 also presents the these NPK compositions of TIA and SA at ISF. From the calculated compositions it follows that at ISF for each nutrient the difference between TIA and TA is equal to the difference between TA and SA, implying that the positions of TIA and SA are at equal distances from the centre of the triangle.

\section{Approaching ISF by continuous balanced NPK supplies}

Many soils are initially relatively rich in K, medium or low in N, and low in P. This is shown for the soil in Fig. 1 of which SAN : SAP : SAK were (in \%) 27.7 : 17.6 : 54.7, as was derived from data of Kwale in Kenya (Smaling and Janssen 1993). If such a soil receives nutrient inputs according to balanced nutrition, the NPK composition of SA will change and finally the composition of SA at ISF is reached or at least closely approached. The soil is then low in N, high in $\mathrm{P}$ and medium in $\mathrm{K}$ (Janssen and De Willigen 2006).

This is because the portions of the input of nutrients that are not taken up by the crop differ for N, P and K. The portions not taken up by the crop partly accumulate in the soil and may partly be lost by leaching, volatilization and erosion. In general, the fraction accumulating in the soil is greatest for P and smallest for $\mathrm{N}$. As a consequence the relative composition of SA increases in $\mathrm{P}$, and decreases in $\mathrm{N}$ and $\mathrm{K}$. Finally, the proportions may become equal to those at ISF.

\section{References}

Beaufils ER (1971) Physiological diagnosis-A guide for improving maize production based on principles developed for rubber trees. Fert Soc S Afr J 1:1-30

Chikowo R, Corbeels M, Mapfumo P, Tittonell P, Vanlauwe B, Giller KE (2010) Nitrogen and phosphorus capture and recovery efficiencies, and crop responses to a range of soil fertility management strategies in sub-Saharan Africa. Nutr Cycl Agroecosyst 88:59-77

Dobermann AD, Dawe D, Roetter RP, Cassman KG (2000) Reversal of rice yield decline in a long-term continuous cropping experiment. Agron J 92:633-643

Feller C, Beare MH (1997) Physical control of soil organic matter dynamics in the tropics. Geoderma 79:69-116

Hoa NM (2003) Soil potassium dynamics under intensive rice cropping. A case study in the Mekong Delta, Vietnam. PhD thesis. Wageningen University, The Netherlands, p 203

Hoa NM, Janssen BH, Oenema O, Dobermann A (2006) Comparison of partial and complete soil $\mathrm{K}$ budgets under intensive rice cropping in the Mekong Delta, Vietnam. Agric Ecosyst Environ 116:121-131
Homès MVL (1961) L'alimentation minérale équilibrée des végétaux. Vol. I. L'alimentation sur milieux dépourvus de fertilité naturelle. Universa. Wetteren. Belgique, p 286

Homès MVL, Verschoor GHJ (1966) L'alimentation minérale équilibrée des végétaux. Vol. II. Extension aux sols réels et à la fumure generalization. Universa. Wetteren. Belgique. p 424

Janssen BH (1998) Efficient use of nutrients: an art of balancing. Field Crops Res 56:197-201

Janssen BH, De Willigen P (2006) Ideal and saturated soil fertility as bench marks in nutrient management. 1. Outline of the framework. Agric, Ecosyst Environ 116:132-146

Janssen B, Menkveld W (1998) Long-term supply of N, P, and $\mathrm{K}$ on the marine loam soils of former sea bottom in the Netherlands. $16^{\mathrm{e}}$ Congres Mondial de Science du Sol, Montpellier, France. Résumés Volume I:288

Janssen BH, Wolf J (1988) A simple equation for calculating the residual effect of phosphorus fertilizers. Fertil Res 15:79-87

Janssen BH, Guiking FCT, Van der Eijk D, Smaling EMA, Wolf J, Van Reuler H (1990) A system for quantitative evaluation of the fertility of tropical soils (QUEFTS). Geoderma 46:299-318

Lantinga EA, Deenen PJAG, Van Keulen H (1999) Herbage and animal production responses to fertilizer nitrogen in 
perennial ryegrass swards. II. Rotational grazing and cutting. Neth J Agric Sci 47:243-261

Le Mare PH (1963) A comparison of the minus-one and the $2^{\text {n }}$ designs for the exploratory investigation of fertilizer requirements. East Afr Agric For J 28:213-218

Loveland P, Webb J (2003) Is there a critical level of organic matter in the agricultural soils of temperate regions: a review. Soil Tillage Res 70:1-18

Smaling EMA, Janssen BH (1993) Calibrating of QUEFTS, a model predicting nutrient uptake and yields from chemical soil fertility indices. Geoderma 59:21-44

Spiertz JHJ, Ellen J (1978) Effects of nitrogen on crop development and grain growth of winter wheat in relation to assimilation and uitilization of assimilates and nutrients. Neth J Agric Sci 26:210-231

Tan PS, Anh TN, Luat NV, Puckridge DW (1995) Yield trends of a long-term NPK experiment for intensive rice monoculture in the Mekong River Delta of Viet Nam. Field Crops Res 42:101-109

Van Keulen H, Van Heemst H (1982) Crop response to the supply of macronutrients. Agric Res Rep 916. Wageningen, The Netherlands, p 46

Weil RR, Magdoff F (2004) Significance of soil organic matter to soil quality and health. In: Magdoff F, Weil RR (eds) Soil organic matter in sustainable agriculture. CRC Press, Boca Raton, Florida, pp 1-43

Witt C, Dobermann A, Abdulrachman S, Gines HC, Wang GH, Nagarajan R, Satawathananont S, Son TT, Tan PS, Tiem LV, Simbahan GC, Olk DC (1999) Internal nutrient efficiencies in irrigated lowland rice of tropical and subtropical Asia. Field Crops Res 63:113-138

Wolf J, De Wit CT, Janssen BH, Lathwell DJ (1987) Modeling long-term crop response to fertilizer phosphorus. I. The model. Agron J 79:445-451 